\title{
Outcomes of Root Canal Treatment: 2 Years Experience in Community Based Medical College, Bangladesh Hospital
}

\author{
Hossen $\mathrm{M}^{1}$, Siddique $\mathrm{MA}^{2}$, Ansary $\mathrm{NB}^{3}$
}

\begin{abstract}
This retrospective study was done in the Department of Dentistry, CBMC'B hospital from January'2009 to December'2010. 223 patients who underwent RCT were purposively selected. Male-female ratio was 1:1.4, mean age of patients were 28.4 years. Most common indication of RCT was gross caries $69.95 \%$, common complications were fractured crown $11(57.89 \%)$, tenderness $5(26.32 \%)$, discharging sinus $2(10.53 \%)$. Over all success rate of RCT was $91.48 \%$.
\end{abstract}

CBMJ-2013; Jan: Vol-02, No-01: P: 29-33

Key words: Root canal treatment, Indication, Complication.

\section{Introduction}

Root canal treatment (RCT) is a procedure that uses biologically acceptable chemical and mechanical treatments in the root canal system to eliminate pulpal and periradicular disease and to promote healing and repair of periradicular tissue. Where a tooth is painful and the dental pulp is irreversibly damaged or a tooth is badly broken down the patient usually faced with a choice of extraction or saving the tooth ${ }^{1}$. Four factors determine the decision to do or not to do a root canal treatment namely accessibility, restorability, strategic value of the tooth and general resistance of the patient which ensures successful treatment. The main objective of root canal treatment is to make the affected tooth or root of a tooth, a proper functional unit which is free from symptoms and pathology and biologically compatible ${ }^{2}$.

Most common diagnosis for doing a root canal treatment (56.4\%) was found to be dental caries ${ }^{3}$. Various studies proved that $28 \%$ of the traumatized teeth required root canal treatment ${ }^{4}$. Pathological involvement of teeth needing root canal treatment varies significantly from superficial pulp inflammation to pulp necrosis ${ }^{5}$. Pulp damage is caused by dental caries, infection consequent to trauma, or infection as a result of operative procedure $^{2}$. Estimates of the success of RCT have varied widely $^{6}$. The potential for an optimal outcome of endodontic treatment reaches up to $90 \%-95 \%$ of the cases when teeth are treated under controlled clinical conditions. However, cross-sectional studies have demonstrated that the reality for the overall population might be somewhat different, with only $35 \%-60 \%$ of the root canal- treated teeth exhibiting no disease ${ }^{7}$. Studies have shown that unprepared areas of the root canal system may harbor bacteria and necrotic tissue that may result in root canal treatment failure ${ }^{8}$. Thus the primary goal of root canal treatment should be to eliminate completely or reduce the microbial population with in the root canal system and to prevent re -infection by providing tight seal. The most common causes of endodontic treatment failure are insufficient cleaning and inadequate sealing of the root canal system ${ }^{9}$. The failure of conventional root canal treatment maybe apparent either by the patient's complaint of pain, swelling, tooth mobility or a discharging sinus or maybe symptom less or becomes evident on radiographic investigation ${ }^{10}$.

1. * Dr. Mahbuba Hossen

Medical Officer, Dental Unit, OPD

Community Based Medical College Hospital

Bangladesh

2. Dr. Mazharul Alam Siddique

Medical Officer, Otolaryngology, OPD

Mymensingh Medical College

3. Dr. Nahid Binte Ansary

Associate Professor

Department of Physiology

Community Based Medical College Bangladesh

* Address of correspondence

Email : bulbulmynm@gmail.com

Mobile : +8801718163186 


\section{Methods:}

This retrospective study was conducted in the department of Dentistry, Community Based Medical College, Bangladesh Hospital from January'2009 to December'2010. Among all the patients of RCT, 223 patients were purposively selected. Those were associated with other complication like discharging sinus, apical infection, other comorbid condition like DM, Hypertension, Periodontally compromised teeth, non strategic teeth and teeth that can be saved through alternate restorative procedure e.g. pulp capping were excluded from the study. Variables in this study were age, sex, type of tooth, success rate and complications. Data were extracted from patient record obtained from patient records obtained at the Department and analysis was done using SPSS software version 16.

Patient record included a detailed history. Patient's socioeconomic status was noted down as it had an appreciable impact on the oral condition of the patient which included oral hygiene, previous dental treatment and awareness regarding getting conservative treatment. The chief complaint with which the patient came was noted. The onset, duration, intensity, aggravating factors of the pain was noted down. A thorough clinical examination was carried out. The suspected teeth were examined clinically for any carious activity. Percussion tests were also carried out on the suspected tooth. The number of the tooth which was indicated for root canal treatment was noted. The teeth was divided into four quadrants and designated as upper left (UL) and upper right (UR) for the maxillary left and right quadrants while the mandibular left and right quadrants were designated as lower left (LL) and lower right (LR). Each quadrant represented teeth from central incisor to the third molar numerically from 1 to 8 . 3 radiographs were taken during the procedure: 1 before starting RCT, 1 diagnostic and another 1 after 3 months.

\section{Results:}

Out of 223 patients majority were female with a male female ratio of 1:1.14. Age of the patients ranged from 9 to 57 years with the mean age 23.4 years. Most common indication for RCT was gross caries (70\%), next common causes were irreversible pulpitis and trauma. In treatment failure group most common complication was fractured crown, then tenderness. The cause of complication was common in patients where root was unidentified.

Gender distribution:

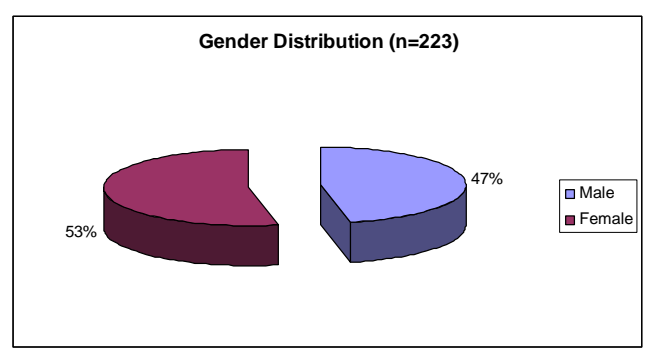

Figure-1: Most of the cases of RCT were female with a male female ratio-1:1.14.

Table 1: Distribution of age $(n=223)$ :

\begin{tabular}{|c|c|c|}
\hline $\begin{array}{c}\text { Age Range } \\
\text { (years) }\end{array}$ & Number & Percentage (\%) \\
\hline $1-10$ & 7 & 3 \\
\hline $11-20$ & 67 & 30 \\
\hline $21-30$ & 78 & 35 \\
\hline $31-40$ & 49 & 22 \\
\hline $41-50$ & 18 & 8 \\
\hline 51 -above & 4 & 2 \\
\hline
\end{tabular}

This table is showing most of the cases were in 21-30 years age group (35\%),then 11-20 years age group. Before 11 years and after 51 years RCT is less in number $(1.3 \%$ and $0.8 \%$ respectively. 
Figure 2: Indication of Root Canal Treatment:

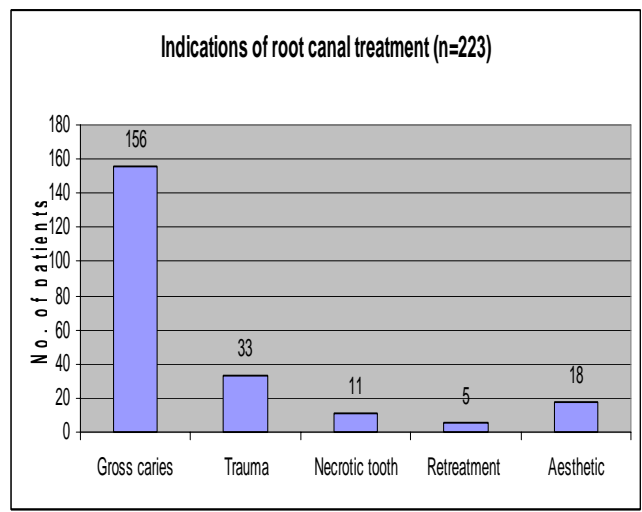

Fig. 2 showing gross caries is the most common cause of RCT (70\%), then trauma (14.79\%) and asthetic (8\%).

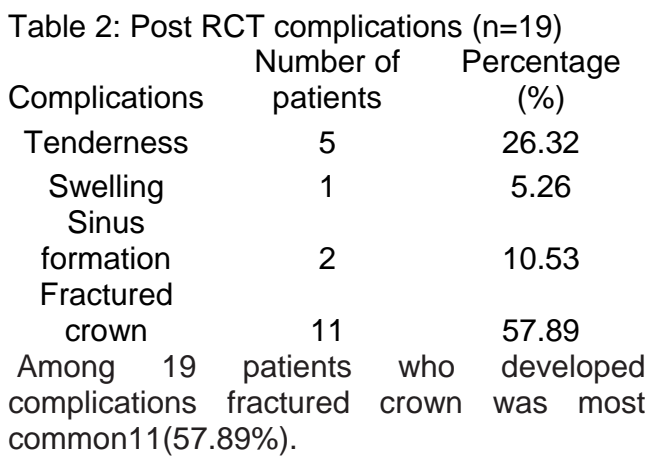

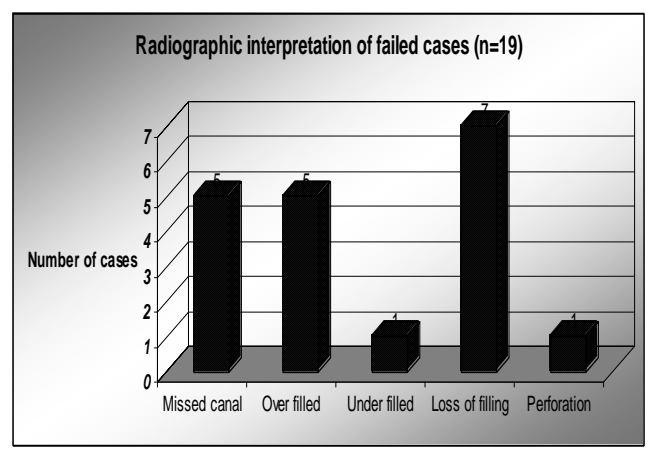

Analysis of x-ray of failed cases showed loss of filling material $(36.82 \%)$ is most common cause of failed RCT, then missed canal and over filled cavity (26.32\%).

\section{Discussion:}

In this institute people come from surrounding villages who are not so solvent and literacy rate is poor. People come to the dental OPD only when they start feeling symptoms for example pain or sensitivity. This study has provided various useful information on root canal treatment.

In this series age of the patients ranged from 9 to 57 with the mean age 28.4. Maximum patient $(65.92 \%)$ of RCT came in $2^{\text {nd }}$ or $3^{\text {rd }}$ decade that is in the younger age group. This indicates that with increased age the resistance of the tooth to decay increases and the tooth becomes less prone to decay. This also indicates to the importance of caries control measures in the younger age group. Preventive measures for young teeth need to be emphasized. This findings is similar to that of Khattak O. et al ${ }^{2}$.

Women have been very passionate and interested about their oral health. Data regarding women and oral health is valid in many countries whereby more women were found to attend dental services more often for various treatments (Nuttal et al., 2001; Oral Health Division, 2004; Todd and Lader, 1991) ${ }^{11}$. In this series out of 223 patients majority of the patients were female with a male female ratio of $1: 1.14$, this is consistent with the findings of Ismail et $\mathrm{al}^{12}$. But some study showed no gender discrimination ${ }^{2}$.

In this series most common indication for RCT was gross caries 156(69.95\%). Necrotic pulp and irreversible pulpitis were the most frequent reasons for performing root canal treatment which are sequel of dental caries. Thus dental caries was found to be the most common cause for performing root canal treatment. when we compare the results with other studies, the percentage of dental caries as a cause is much higher. Ridell and Sundin in their studies found caries to be responsible for $56.4 \%$ of the root treated teeth ${ }^{13}$. The present study also showed that the most of the tooth which was indicated for root canal treatment was the mandibular first molar $110(49.35 \%)$. This was similar with previous studies done by Ridell and Sundin ${ }^{13}$. The most probable reason for that was that it generally is the first tooth to erupt in the oral cavity, hence it was more prone to caries if preventive measures like fissure sealants were not undertaken. The results also 
showed that the mandibular teeth $147(65.92 \%)$ were more prone to dental caries and hence to root canal treatment as compared to maxillary teeth which were indicated for root canal treatment in remaining cases. Mandibular teeth are more prone to food stagnation on occlusal surfaces as compared to maxillary teeth.

The most frequent teeth involved in trauma were the anterior teeth which included both mandibular and maxillary teeth. This was probably because the anterior teeth because of their location are more susceptible to injury as compared to the rest of the teeth.

A successful result for RCT relies on adequate removal of micro-organisms form the root canal system and prevention of recolonization or propagation of residual microorganisms through the placement of well extended homogenously dense root filling and adequate coronal restoration ${ }^{14}$. In the present study the most common causes of root canal treatment failure observed were either poor, under, or missed canal. This is in agreement with many other studies which show that quality of root canal filling influence the prognosis of endodontic therapy ${ }^{15-17}$. Inadequate preparation and filling of the root canal system mean that residual spaces and microorganisms are left behind which ultimately result in endodontic treatment failure. According to Cohen and Burns, $1 \mathrm{~mm}$ of the canal with the diameter of $0.25 \mathrm{~mm}$ can harbor nearly 80,000 Streptococci ${ }^{18}$. Literature shows that $1 \mathrm{~mm}$ loss in working length increased the chances of endodontic treatment failure by $14 \%$ in teeth with apical periodontitis ${ }^{19}$.

The concepts of success and failure of endodontic treatment is a very complex issue. According to Strindberg (1956) the only satisfactory post-operative outcome after a certain post-operative period is a clinically symptom-free tooth and the radiological appearance of a normal peri-apex ${ }^{20}$. Thus a failure can be defined as the presence of signs and symptoms that indicate disease or problems. Both clinical assessment and the use of radiographs are vital for evaluation. More than half of teeth in this sample were treated with pre-existing periapical radiolucencies. Generally, teeth with periapical radiolucencies had better success rates than those without (Peak et al., 2001) ${ }^{21}$. However, there were $6.9 \%$ cases of failure after retreatment in the study of Ismail at el in $2008^{12}$.

In my study failure rate was $8.52 \%$. In failed cases common cause of failure was loss of temporary filling material $7(36.84 \%)$. Due to loss of filling material microorganism colonizes and patient failed to visit in time. Other causes of failure are missed canal and overfilled canal $26.32 \%$ each and under filled and perforation of root in $5.26 \%$ each. Calcified canal, curved root, additional canal, narrow canal are difficult to to treat successfully. Most common complication after RCT was fractured crown 11(57.89\%). This is probably due to less strength of RCT tooth.

A success rate of $90-95 \%$ is commonly cited as a clinical expectation and some studies have observed success rate at this level. A systemic review of literature from 1966-2004 identified 306 articles thatinvolved the outcomes of RCT, the review observed success rate of approximately82\% over a 5 year follow up ${ }^{6}$. In my series the success rate is $91.48 \%$. This high success rate may be due to less follow up time (which is 6 month to 1 year) and careful selection of cases.

\section{Conclusion:}

Dental caries is the main cause of RCT and RCT is an useful dental procedure to maintain sound dentition. After RCT restoration procedure can reduce the failure rate. 


\section{References}

1. Chng HK, Chen NN, Koh ET, Lam ECE, Lim $K C$, Sum CP. Guideline for Root Canal Treatment.Singapore Dental Journal. December 2004; Vol 26. no. 1:60-62.

2. Khattak O, Ahmed A, Shahnawaz A, Javed Q, Minhas SA. Reasons for carring root canal treatment -a study. Pakistan Oral \& Dental Journal. June (2009) Vol 29 no.1:107-110.

3. Ridell $K$, Sundin B, Mattson L. Endodontic treatment during childhood and adolescence. Swed Dent J 2003; 27: 83-9.

4. Puglesi DM, Cunla RF, Delbem AC, Sundefeld $M L$. Influence of the type of dental trauma on the pulp vitality and time elapsed until treatment. Dent Traumatol 2004; 20: 139-42.

5. Spangberg LS. To do a "root canal". Aust Endod J 2003; 29: 13-6.

6. Gilbert $\mathrm{GH}$, Tilashalski KR, Litaker MS, Mcneal SF, Boykin MJ, Kseeler AW, Outcomes of root canal treatment in dental practice based research network practices.General Dentistry. 2010,28-36

7. 7,. Tavares PBL, Bonte E, Boukpessi T, Siqueira JF, Lasfargues JJ. Prevalence of Apical Periodontitis in Root Canal-Treated Teeth From an Urban French Population: Influence of the Quality of Root Canal Fillings and Coronal Restorations.JOE, June 2009. Vol 35 no. 6:810-813.

8. Siqueria JF, Araujo MCP, Garua PF, Fraga RC, Sabota Dantas CJ. Histological evaluation of the effectiveness of five instrumentation techniques for cleaning the apical third root canals. J Endod 1997; 23: 499-502.

9. Siqueria JF. Etiology of root canal treatment failure. Why well treated teeth can fail. Int Endod J 2001; 34: 1-11.

10. Jimena ME. Endodontic needs of geriatric patients in private practice. J Philipp Dent Assoc 1998; 49: 5-21.

11. Nuttal NM, Steele JG, Pine CM, White $D$ and Pitts NB (2001). The impact of oral health on people in the UK in 1998. Br Dent J, 190(3): 121-126.

12. Ismail NM, Ismail AR, Wan Nor Syuhada WAR Root canal treatment in Hospital Universiti Sains Malaysia Dental Clinic - a 5-year retrospective study Archives of Orofacial Sciences (2008), 3(1): 23-28

13. Ridell K, Sundin B, Mattson L. Endodontic treatment during childhood and adolescence. Swed Dent J 2003; 27: 83-9.

14. Soikkonen KT. Endodontically treated teeth and periapical findings in the elderly. Int Endod J 1995; 28: 200-203.
15. Noor N, Maxsood A, Kaleem K. Cross sectional analysis of endodontic failure in PIMS. Pakistan Oral \& Dent Jr 2008; 28: 99102.

16. Nie Q, Lin J. Comparison of intermaxillary tooth size discrepancies among different malocclusion group. Am J Orthod Dentofacial Orthop 1999; 116: 539-44.

17. 17 Alkofide E, Hashim H. Intermaxillary tooth size discrepancies among different malocclusion classes: a comparative study. J Clin Pediatr Dent. 2002; 26: 4383-87.

18. 18 Cohen S, Burns RC. Pathways of Pulp 6th ed. St Louis Mosby; 1994.

19. 19 Chugal NM, Clive JM, Spangberg LS,. Endodontic infection: some biologic and treatment factors associated with outcome. Oral Surg Oral Med Oral Pathol Oral Radiol Endod 2003; 96 :81-90.

20. Strindberg $L Z$. The dependence of the results of pulp therapy on certain factors. An analytic study based on radiographic and clinical follow-up examinations. Acta Odontol Scand,1956, 14(Suppl 21): 1- 175.

21. Peak JD, Hayes SJ, Bryant ST and Dummer $P M H$. The outcome of root canal treatment. A retrospective study within the armed forces (Royal Air Force). Br Dent J, 2001;190(3): 140-144. 